\title{
A MODEST CRITICAL PEDAGOGY FOR ENGLISH AS A FOREIGN LANGUAGE EDUCATION
}

\author{
Mi Kyong Kim
}

Sunchon National University

cpefl2006@daum.net

\section{Vikki Ann Pollard}

Deakin University

vikki.pollard@Deakin.edu.au

\section{ABSTRACT}

This paper uses the introduction of critical pedagogy to an English as a Foreign Language class in the Republic of Korea as a case study for a "modest critical pedagogy" (Tinning 2002). Focusing on the stress and resistances experienced during the introduction, we suggest a modest critical pedagogy that 1 ) makes the paradigm itself an explicit part of the curriculum, 2) redefines the emancipatory aspect of critical pedagogy to focus on "what we expect students to do and what we as educators do" (Gore 1993, 154) and, 3) re-examines the facilitator role of teachers. We use the work of Michel Foucault (1983) to suggest a critical pedagogy that asks students and educators to examine previous experiences of education and the effects of these experiences upon a sense of self, that explores the limits of critical pedagogy in terms of a sense of self and that experiments with the possibility of going beyond these limits to develop a different sense of self. This shift to an examination of the effects of critical pedagogy re-defines its emancipatory potential.

Keywords: critical pedagogy; English as a Foreign Language; resistance; South Korea

\section{INTRODUCTION}

The introduction of critical pedagogy has proved stressful for both teachers and students (Blignaut 2014; Chiu 2009; Currie and Knights 2003; Ellsworth 1989; Gore 1993; Kim 2015; Lin 2004; Tinning 2002). In light of this, there is a need for research that first,

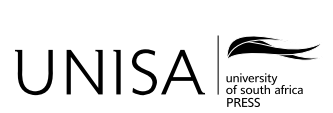

Education as Change Volume 21 | Number 1 | 2017 | pp. 50-72 www.educationaschange.co.za
DOI: http://dx.doi.org/10.17159/1947-9417/2017/492 Print ISSN 1682-3206 | Online 1947-9417

(C) 2017 The Authors 
focuses on the stress and resistance experienced by teachers and students, including the tendency for innovators to be overwhelmed (Lin 2004) and second, suggests ways of practising critical pedagogy that take this stress into account and that are local and contextualised (Gore 1993; Nozaki, Openshaw and Luke 2005). The aim of this paper is to contribute to this form of research. We do so through a case study of a project that implemented critical pedagogy in an English as a Foreign Language class in a university in the Republic of Korea undertaken as part of a $\mathrm{PhD}$ project. The project was extremely stressful for both students and the lone teacher-researcher Kim, the first author of this paper. Reasons for the resistance and stress include a shift from a teachercentred to student-centred paradigm, the expectation that students would examine socially contentious issues in their assessment tasks, group work and the shift of role for the teacher from directive to facilitative.

This case has been written up before (Kim 2015); however, the unique contribution of this current paper is to contextualise the stress and resistances in terms of critiques of critical pedagogy and to suggest a localised form of critical pedagogy. This local form pays particular attention to how to practise critical pedagogy - currently an underexamined area. Our version of a localised critical pedagogy rests upon three important aspects of practice, these being: 1) making the paradigm itself an explicit part of the curriculum, 2) redefining the emancipatory aspect of critical pedagogy to a focus on what we expect students to do and what we as educators do (Gore 1993, 154) and, 3) re-examining the facilitator role of teachers. We have taken a poststructuralist approach to a "modest critical pedagogy" (Tinning 2002) to argue that critical pedagogy assumes certain subject positions for teachers and students and that this assumption can form the basis of a modest critical pedagogy. We use the work of McWilliam (2009) to suggest moving from an understanding of the teacher as facilitator to meddler-in-the-middle. Finally, the work of Michel Foucault (1983) is used to suggest a critical pedagogy that examines its own limitations and attempts to move beyond them. This localised redefinition of critical pedagogy is aligned with the need for a modest critical pedagogy.

This paper consists of three sections. First, we offer a case study of the initial PhD project. The case study explores student and teacher resistances and stress. Second, we address three themes drawn from the case study by analysing them in the context of critiques of critical pedagogy. In doing so, we offer suggestions for practice. Lastly, we argue that our work is aligned to a "modest critical pedagogy" (Tinning 2002) and is appropriate when introducing critical pedagogy to a teacher-centred context. 


\section{INTRODUCING CRITICAL PEDAGOGY TO A KOREAN ENGLISH AS A FOREIGN LANGUAGE COURSE - A CASE STUDY}

\section{The motivation and the curriculum}

The case upon which we base this study of critical pedagogy is of the experiences of the first author Kim, a Korean English as a Foreign Language (EFL) lecturer, who, as part of her PhD project (2002-2006), used a critical pedagogy paradigm to design and teach an EFL course in a Korean university. The resistance to this project, in particular the project-based learning element, has been written up previously (Kim 2015). This paper is somewhat of a companion piece to the 2015 paper. Kim's aim was as much to challenge her "usual" style of teaching as to challenge the normal order of EFL in the Republic of Korea, hereinafter referred to as Korea. Kim believed that the critical pedagogy paradigm supported her desire to challenge the teacher-centred, rote learning that was the norm for teaching EFL in Korea and better prepared her students to be critical users of English (Canagarajah 1999; Kim 2015; Pennycook 1994; Phillipson 1992). In order to produce critical users of English, Kim aimed to teach students to question sources in English in an attempt to overcome the tendency to give credit to the sources because they were in English. Data on the student and teacher experiences of the newly designed 15 -week course were gathered through journals kept by the students on the course, student interviews after the course, and Kim's teacher's journal. The second author was doing a $\mathrm{PhD}$ at the same institution as Kim and they formed a relationship of mutual support and enjoyed discussing critical pedagogy. The view of the second author is based on a feminist perspective, influenced especially by the edited book by Luke and Gore (1992). This view includes questioning notions of student-centred pedagogy from a poststructural feminist perspective.

While Kim expected to be confronted with a great challenge, she did not expect to meet such fierce resistances, including her own. She found students were highly resistant to the critical pedagogy paradigm, the group-work nature of the tasks and the critical pedagogical focus on choosing topics with a social justice bent. Kim also found that her own stress levels were such that she felt demoralised and unable to continue. She wrote about this in her journal, as we describe below. In hindsight, we believe Kim suffered from the "pedagogical fatigue factor that comes from dealing with student resistance" (Tinning 2002, 230) and believe it is important to look more closely at this in order to offer support for others aiming to go down a critical pedagogy path. This includes exploring how educators feel when they "fail" (Lin 2004). Lin (2004) reported similar feelings after introducing critical pedagogy to a teacher-education programme in Hong Kong. These feelings actually stopped her from writing about the experience; "For some time, I had been so confused and agonised that I could not carry on with the writing of this chapter" (284). Likewise, it has taken Kim several years to confront 
the challenge of writing about her experiences of introducing critical pedagogy to her English as a Second Language teaching in Korea.

The initial motivation for Kim in designing her $\mathrm{PhD}$ project was her recognition that the development of English proficiency as a key issue for Korea (Samuel 2000) jarred with the traditional English teaching and learning approach generally utilised. That approach was generally "a traditional pedagogy with an emphasis on grammar/ translation and reading skills with some provision for listening" (Han 2000; Park and Kim 2014; Shin 2003; Sung 2008). This was the primary approach that Kim had used and the prevalent form of EFL pedagogy experienced by her students (see below). Kim realised that the teacher-centred traditional approach underprepared students for the English exams they were expected to take which have a far more active approach to English. This mismatch between teaching practice and the "examination culture" (Wong 2008, 974) resulted in a large amount of private tutoring in Korea (MOE 2014). Kim was interested in developing a form of active EFL teaching practice that would enable students to become proficient speakers of English.

Kim was also interested in addressing the globalising effects of English in Korea. Phillipson (1992) argues that the spread of English acts as a form of linguistic imperialism, while Pennycook (1994) and Canagarajah (1999) see the spread of English as too complicated to be considered either benign or evil. One of the major problems with a non-critical form of ELT that uncritically accepts English as an inescapable global force is that it requires students to learn how to "fit" into pre-existing modes of being using a pre-existing mode of English. Elsa Auerbach, a teacher and scholar of critical pedagogy (1995) describes the grammar/translation method as follows:

grammar-driven curricula [provide a] situational, survival-oriented model focusing on language skills or competencies deemed necessary to fit in or function "successfully" within particular institutions (e.g., the workplace) or in relation to a range of interactional contexts (e.g., banking and health care). (Auerbach 1995, 12)

The curriculum for this method derives from experts defining what ought to be known for learners. This results in an "overriding concern [to] linking instruction to employability and economic self-sufficiency" (ibid, 14). Auerbach argues that this approach "serves as a mechanism of social control, disempowering for both students and teachers. Its underlying assumption is that learners should assimilate into pre-existing structures and practices without questioning the power relations inherent in them" (op cit). It was this form of teaching and learning that Kim wished to challenge and she believed that critical pedagogy would offer a method for such a challenge.

\section{CRITICAL PEDAGOGY IDEALS}

Kim's critical EFL pedagogy for her PhD project was developed primarily through drawing on the works of Paulo Freire $(1970 ; 1985)$ and Canagarajah (1999). This work allowed her to understand that teaching and learning are "implicated in the exercise of 
power and domination in society" and that "what is learned orientates the student to the world view and to the ideologies of the status quo" (Canagarajah 1999 quoted in Kim 2015, 75). Critical pedagogy aims to counter this by developing problem-posing students; "the students - no longer docile listeners - are critical co-investigators in dialogue with the teacher" (Freire 1970, 45). Students and teachers engage in a "genuine dialogue... [and] work as partners in a unified quest for a critical consciousness" (McLaren 1994, 232). The aim is that, through dialogue, students critique current relations of power and attempt to impact upon them through action. "The emancipatory rationality that underpins a liberatory pedagogy "is based on the principles of critique and action"” (Giroux quoted in Luke 1992, 29).

Kim was attracted to the Freirian technique of "problem-posing" wherein students raise problems of the social world that may then impact upon that world. Critical pedagogy demands significantly different roles for teachers and students than does "banking education". It is a student-centred pedagogy that attempts "to challenge traditional notions of who has authority in and on education" (Cook-Sather 2002, 4). In EFL contexts like this research study, Hall (1999) further links a student-centred approach to "problem-posing" education by discussing the aspects of the student-centred approach such as its "emphasis on negotiation, the intertwining of method, syllabus and teaching, and its firm foundations of teacher-student interaction" (17). Understanding this thesis, Kim conducted a study to introduce critical pedagogy to her EFL class.

\section{Learner-centred project-based learning}

Kim decided that in the Korean context in which she was situated, a project-based learning (PBL) approach would be best suited for a critical pedagogy paradigm. She has written in greater length of the PBL approach adopted for the 15-week course (Kim 2015). Briefly, the PBL approach meant that students worked together in small groups to develop a website on an important social issue and did an oral group presentation. The website was to be written in English. Students engaged in activities of deciding topics, researching information, and compiling evidence. All of these involved intense negotiations between students (Kim 2015,79). Also involved were 10 minutes per lesson of reading and grammar, lengthened to 20 minutes after several weeks due to student complaints that they were not learning enough English. For the same reason, class time was given over to practising the oral presentations towards the end of the course.

The students were all Korean and spoke the same language, Korean. Like other classes, they were expected to use their language rather than English in this course. The students were primarily first year students, with a few second/third year and final year students, from six faculties: humanities, social sciences, natural science, engineering, human ecology, and business administration. The course was one of the compulsory liberal arts credit subjects. The number of the enrolled students was 58 in various departments of the university since this two-credit course was one of the 30-credit liberal 
arts subjects and was compulsory. The students were enrolled at the following faculties: humanities (10 or $17.2 \%)$, social sciences (9 or $15.5 \%)$, natural science (5 or $8.6 \%$ ), engineering (18 or $31 \%$ ), human ecology (7 or $12.1 \%$ ) and business administration (9 or $15.5 \%$ ). Most students (40 out of 58 ) were first year students who were less than 20 years old. Considering that the course was held in the first semester of the year, the course was the first course for most of the students after they entered the university, and naturally appeared unfamiliar to them. In addition, more than half of the students (32 out of 58) were male.

\section{DATA COLLECTION METHODS}

The empirical research undertaken by Kim in her initial research project was guided by the following two questions:

1.How did the students perceive the student-centred curriculum?

2. What were the teacher's perceptions on the implementation of the course? In the interpretation of the findings, Kim employed triangulation as a research strategy to reduce the possibility of bias (Denzin 1978). Data were collected from two sources: student participants and the researcher/teacher. In addition, different instruments were used to collect different data types (e.g., learner journals, teacher journals and interviews). The study used three data collection methods: learner reflective journals, teacher journals and interviews with students after the course ended. The journals and interviews were conducted/written in Korean and translated by Kim. The number of the journal participant students was 23. Each week of the course, students were asked to reflect on websites that they browsed and where they read information. Most students were male (15 out of 23) and in their first year (17 out of 23). There were 10 interview sessions with 11 interviewees and they took place midway through the course. Again, most participants were male (7 out of 11) and in their first year ( 7 out of 11).

\section{Reflective research journals and interviews}

Student reflective journals allow students to reflect upon their learning (Hiemstra 2001). Kim expected students to reflect upon the activities in which they were involved. These reflections were not formally assessed but were used by Kim to guide her teaching and research. In this way, she believed she could develop her new facilitator role in a manner that was immediate. The journals were structured around the following questions: What did I do? What information about the topic did I already know? What did I learn? Troubles? Questions? Students were also invited to provide examples and discuss other matters. The teaching journal Kim kept for the duration of the project consisted of a format of "observation/reflection/plan" as recommended by Shafer 
(1995). At each stage, Kim included lesson plans and worksheets for each week, and wrote in the journal on the three themes: the process of PBL, problems and suggestions. This teaching journal was written mainly after class but also, when necessary, in the midst of a class.

Interviews were conducted in Korean with 11 participants in the teacher's office at the university. They were all recorded and translated by the researcher. The semistructured interviews aimed to explore the students' perspectives on the student-centred approach to learning English. The interview aimed to elicit students' interpretations of and responses to the dynamics of a new learning context, for example, the changing roles of learning in the project-based approach. It was hoped that individual interviews might involve an explicit examination of students' perspectives on the research issues.

\section{Data analysis}

The qualitative data were analysed using NUDIST. For analysis, the data were coded according to themes. Thematic analysis was used to examine project journals, teaching notes, project products and interviews. The integration of the analyses of all the data from each student contributed to the development of an understanding of each student's experience in producing projects aligned with the course objectives. Kim used an inductive process to discover critical themes emerging from the data (Bogdan and Biklan 2003). For the data, NUDIST was used to manage the descriptive documents and transcripts, enabling storing, browsing, indexing, and coding of all text. NUDIST was also used to explore the documents and search for patterns and themes that emerged from the text. As the data were explored, text annotations were coded and an index system was established. Search tools within the software were used to link, explore, and ask questions to determine relationships and establish hierarchies within the data. Transcriptions of the interviews provided the text for the initial coding and indexing of data. Other text imported into the software programme included text from learner journals and teacher journals. Most of the data were converted into text files from Microsoft Word documents that were typed by the researcher from the raw data.

\section{FINDINGS}

For the purposes of this paper, Kim shared the data with the second author and it was re-analysed along the themes of resistances and stress. In this section, we discuss the following themes: students resisting the critical pedagogy paradigm, students resisting engaging with social issues, students resisting group work, students embracing critical reflection and teacher stress and resistance, including the change to a facilitator role and coping with intense resistance. After the presentation of these themes, we look more closely at them in terms of a critical analysis of critical pedagogy. 


\section{Students resisting the paradigm}

I'm giving up. (Project journal 2: April 27, 2003)

The students found adapting to the critical pedagogy paradigm extremely difficult. As described above, the grammar/translation method was the commonest form of EFL teaching in Korea at the time of the project. The interview data revealed that all 11 of the students interviewed had only previously experienced teacher-centred English education. The teaching methods that the students had experienced were represented by three categories: grammar and translation, drill with test bank items and playing a tape recorder for listening practice. The following interview excerpts typified the students' previous experiences of learning English:

The teacher said to us, "memorise this" and we just did it. (Interview: Jun, $1^{\text {st }}$ year male student in social science)

In my middle school, the teacher explains grammar. In my high school, the teacher just translates the textbook. (Interview: Hyon, $1^{\text {st }}$ year male student in business administration)

The course had many things different from the classes that we had during high schooling. So we are busy and keep getting lost during the class. (Email message 21: March 31, 2003)

This type of learning is in stark contrast to the PBL method adopted by Kim that gave students a significant amount of autonomy to decide on a social issue to study, work together to develop the topic, present it in website form and do an oral presentation to the class. It was also a significant shock to the students that the teacher's role was very different. The assessment was primarily based on group work. Through activities including deciding on topics and gathering, compiling and analysing information while carrying out the project, the students were involved in the process of knowledge negotiation as a group. Each group had a group leader. The responses of students to this new form of learning are typified in the following interview excerpts:

I'm worried about the course this semester. Frankly speaking, I think I'm not sure and don't know what to do and I doubt our group members can follow it. This is too different from I thought. (Project journal 27: March 11, 2003)

In fact, there are too many things to do. I feel burdened. (Project journal 16: March 18, 2003)

Professor, initially, I was puzzled and complained a lot about the course as we haven't heard about the way of teaching, and known the methodology. (Project journal 6: June 3, 2003)

The critical pedagogy paradigm with the new roles expected of students and teacher caused a great deal of stress for students. 


\section{Resisting the critical pedagogy principle of transformation}

Group work is an essential element of PBL, thus Kim's design was based on studentcentred group-work activities. The students had to form groups, choose their own topics of interest and develop an English language website on the topic. Given the critical pedagogy paradigm, Kim hoped that students would choose topics related to social justice and encouraged them to do so by introducing and discussing the possibility in class. This attempt aligned with the emancipatory principle of critical pedagogy - problemposing that attempts to raise a critical conscience and leads to social transformation and empowerment. However, the reality was that the students in the project tended to choose benign topics for their group work and website.

The first topic, AIDS that I suggested, has changed into something more usual as it seems rather serious. So, we talked about Ramen, instant noodles or soccer. (Interview: Won, $2^{\text {nd }}$ year male student in business administration)

Yes. We have to be responsible for the project. We're really busy and devoted to the work. After finishing this later, I feel like I would be an expert of football. (Interview: Hyon, $1^{\text {st }}$ year female student in human ecology, emphasis added)

Of all the topics chosen, only two could be considered aligned to the emancipatory principle of critical pedagogy; these were a study of North Korea and a study of the Daegu subway calamity. Kim found only the latter offered any critical understanding. The North Korean website very much reflected the strict state censorship of North Korea by the South Korean government. The Daegu website, however, included some criticism of the legal system. Overall, Kim was deeply disappointed by the lack of engagement with deeper social issues.

\section{Resisting group work}

The interview data revealed that some of the students enjoyed the group-work experience.

It is good. It is effective. We can discuss and express our thoughts. We can also hear others' thoughts. (Jong, $1^{\text {st }}$ year male student in information engineering)

However, many other students reported finding the group work difficult and a cause of stress. The students were expecting teacher-centred learning and had little experience with group work. Students said that they had to make up for some of their group members who rarely participated in the group activities.

I'm honestly so angry. To be honest, I can't say I'm active but this is too much. They just don't want to do their works and put them to others. I don't want to do it either. (Project journal 16: March 27, 2003)

Well, it can be summed up as depression, discouragement, low spirits, and trouble with group members. (Interview: Joo, $4^{\text {th }}$ year female student in humanities) 


\section{Students embracing critical reflection}

The one element of the course that students coped with and that supported their progress in the critical pedagogy paradigm was the student reflective journals. The critical reflections that students wrote as part of the research project - they were not assessed - were an extremely productive way not only for them to manage their stress and resistance but to dialogue with Kim. Through the journals the students expressed their feelings. Kim responded to this in class and negotiated the curriculum along the way. One student said knowing that their frustrations were taken into account by the teacher influenced his response to the course:

I understand that you read our project journals and found that we had a lot of problems with the group work. And you changed what you initially planned to do. In addition, you included enough writing composition lessons, which helped me a lot with my writing. Also, the fact that Professor got to know that we struggled greatly helped us emotionally. (Project journal 6: May 6, 2003)

After they understood that their reflections, discussions and emails were responded to in class, the students attempted to engage in the course curriculum. One student even made a suggestion that the course should include a bulletin board so that the students could share their opinions and understandings.

\section{Teacher's reflections}

In this section, we present Kim's reflections based upon her researcher diary of her experiences of resistance and stress when teaching the new course. Midway through the course, Kim learned that her nickname was "Iron Lady" or "a lady who wouldn't have any blood if her forehead was pricked with a needle" (a Korean expression referring to a strict/mean person). The distress of this nickname and the stress of the new paradigm for Kim really came to the fore on Teachers' Day. This is very special in Korea as it is a time for students to show their appreciation to teachers, usually through notes and a small gift, such as a plant. Kim used to be one of the most popular teachers and usually received lots of appreciation notes and little presents from her students on Teachers' Day.

However, on Teachers' Day, which fell during the middle of the research project, Kim received nothing, not even a note. To cover her shame she bought herself a plant to put on her desk. Kim pondered the changed perceptions of her students and wrote in her journal, "Why had I become Iron Lady? Perhaps I thought unconsciously that the strict and disciplined appearance of an iron lady would help maintain my authority in a student-centred approach, and keep the learning process in order. Perhaps I was concerned that the course would descend into chaos". Kim's stress was exacerbated by the fact that she was alone in introducing critical pedagogy to her institution and that her support was located at her Australian university, including the co-author of this paper. 


\section{Teacher as facilitator: Free students in large classes}

During the interview sessions, the students "freely" expressed their confusion, frustration and anger towards Kim. Through the weekly learner journals, the students "freely" showed their struggles. Kim became confused and hurt. Then, she became angry with their "free" attitudes. She remembers thinking "I am teacher, you are students. How dare you?". She took their attitudes as misbehaviour or even rude behaviour. She began to realise that the issue was related to the changing power structure between teacher and students in the classroom. In a traditional "banking-education" classroom, the teacher has an authority as a provider of knowledge; in the student-centred PBL classroom, the teacher's position shifts to a facilitator of learning. The asymmetrical power structure confused Kim and contributed to her anger. Another factor related to Kim's stress was the size of the classes - more than 40 students! In fact, the difficulty of dealing with a class of 47 students was muddled from the initial stages. Kim found juggling so many students and their needs in the role of facilitator physically exhausting and emotionally draining.

\section{CRITIQUING CRITICAL PEDAGOGY TO REDEFINE PRINCIPLES}

The experiences of Kim and her students were unique in that they are engagements at the local level with a pedagogy developed elsewhere. However, as we see in this section, they were not unique in the broader context of critical pedagogy. In this section, we contextualise the experiences of Kim and her students within critiques of critical pedagogy. The attempt to contextualise critical pedagogy to local efforts is an ongoing concern. Gore $(1993,46)$ wondered if critical pedagogy was a US-centric pedagogy and if a critical pedagogy outside of the US "locates itself more clearly in particular, practical, political concerns rather than in abstract, universalising concerns".

In a similar vein, Nozaki, Openshaw and Luke $(2005,3)$ write "we need to engage with regional, local and community-specific uptakes and contestations, transformation, and transliterations of the educational discourse and practices that now traverse borders". Lin $(2004,276)$ argues that critical pedagogy needs be contextualised to local contexts. Our analysis of the experience in Korea contributes a localised and particular understanding and offers some suggestions for implementation. The analysis of this Korean project presented below is based on three themes: the "alien" nature of critical pedagogy, the principle of emancipation/empowerment and the facilitator role of the teacher.

\section{Resisting the "alien"” paradigm}

The students involved in Kim's project had a very difficult time coming to terms with the new demands of critical pedagogy. In critical pedagogy, the lives and experiences 
of students become central to the curriculum and students are expected to be critical co-developers of knowledge who work together and with their teacher to question assumptions and prior knowledge in order to effect change. Supported by the teacher as facilitator, various techniques such as "problem-posing, dialogue, the role of the teacher [and] personal narrative" (Derince 2011, 383) are utilised to support students to bring their experiences into the curriculum. These techniques were wholly unfamiliar to the students in Kim's project who had only experienced the grammar/translation method of learning English. Suddenly, they were expected to accept a new role for their teacher, to discuss social issues and their experiences of these with peers, to decide upon social issues worthy of website development, to develop the website and to be a proactive member of a group. Their discomfort, far from being unusual, is to be expected when critical pedagogy is introduced into a context where teacher-centred methods, such as the grammar/translation method, dominates (Chiu 2009; Currie and Knights 2003).

The word "alien" recurs in research analysing attempts to introduce critical pedagogy to teacher-centred contexts. Chiu (2009) found that the "nurturing of critical thinking [is] alien to the norms to which students have become accustomed" (42). In their attempt to introduce critical MBA pedagogy, Currie and Knights (2003) note that students from South-East Asia described the student-centred approach as "alien" (38). This is because students are "often used to a more prescriptive or disciplinary approach where the teachers imposed their authority and expertise" (op cit). While the shift to a student-centred pedagogy produced anxiety for both students and academic staff, Currie and Knights found that South-East Asian students are becoming more critical in their MBA courses and surmise that this is due to the recognition that to accept managerial theories carte blanche is neo-imperialist.

In his attempt to introduce critical pedagogy to a South African teacher-education course, Blignaut (2014) also experienced a great deal of student resistance to the paradigm, although the word alien does not feature here. Students were angry about having to adopt a far more active approach to their learning and were disappointed with the role Blignaut took as a teacher. "They were too familiar and felt comfortable with a model of teaching where learners were seen as sponges, absorbing the standardised 'knowledge' dispersed by teachers" (277). The students felt the teacher was "unprepared" (278) and did not give the students the answers they thought were required to succeed in the class. "The most important thing is to get the 'correct' interpretation from the lecturer. What I or the group think is of no relevance and value" (278) one of the interviewed students argued. Blignaut noted that the stress decreased as he became more experienced over several iterations of the course.

It has become crucial to argue that when critical pedagogy is introduced students are taught about the paradigm. This includes critiques of critical pedagogy as a teaching and learning paradigm. Pittard $(2015,330)$ writes that critical pedagogues tend not to critique critical pedagogy in the same manner in which they critique the social realm. This avoidance has led to the position that critical pedagogy is not really taught to 
those who are its subjects. Gore (1993) argues "there has been a tendency to emphasise what we do and say for others rather than what we do to ourselves and ask others to do to themselves". Rather than reflect upon critical pedagogy we expect students to do critical pedagogy. This has led to claims that critical pedagogy is a form of mind control. Freedman $(2007,444)$ argues "critical educators typically enter the classroom with preformulated political objectives. Their goal...to alter students' ways of thinking to conform with preconceived notions of what constitutes critical thought". This challenge can be met if, when introducing critical pedagogy to a teacher-centred context, the pedagogy itself becomes a focus of the curriculum. Rumashiro (2015) argues that students should be taught how to "engage with relevant aspects of critical pedagogy and extend its analysis to their own lives, but then critique it for what it overlooks or forecloses" (49).

Making critical pedagogy an explicit aspect of the curriculum seems like an important initial step for introducing critical pedagogy. The curriculum can be developed in order to allow a growing critical awareness of the principles of critical pedagogy and of critical pedagogy as a way of thinking and the effects of this way of thinking. However, this can only be achieved if the underpinning principles of critical pedagogy are re-framed to the particular context. This type of change is considered in the next section.

\section{THE PRINCIPLE OF EMANCIPATION}

We have described how Kim and her students struggled with the principle of emancipation/empowerment. The students found it difficult to focus on what Kim considered important social issues - AIDS, North Korea, subway accidents. Kim found it difficult to cope with what she saw as "freely expressing" students. In this section we critically analyse the principle of emancipation in order to suggest a re-framing of it for a localised version of critical pedagogy. We suggest that emancipation can be focused on a "micro-level of change" (Pittard 2015, 332), in this case from external social change to a consideration of how students learn, the limits this places on their learning and critical pedagogy as a different form of learning with its own limitations and freedoms. We suggest that dialogue as writing and group knowledge negotiation are important to this end.

The principle of emancipation is one of the most critiqued aspects of critical pedagogy (Ellsworth 1989; Gore 1993; Luke and Gore 1992; Pittard 2015). This principle has been described in many different ways and differs according to the particular philosophical stance of authors (Pittard 2015). In this paper, we understand the emancipatory principle as the aim to:

understand, reveal and disrupt the mechanisms of oppression imposed by the established order, suturing the processes and aims of education to emancipatory goals. (Grande 2015) 
Kim attempted to change what she understood as her oppressive teaching practices and hoped the students would choose topics that revealed and disrupted oppression within the social realm. This was generally a failure in the initial project. In this, we are not alone as Pittard $(2015,330)$ argues that critical pedagogy has an "unfulfilled promise of emancipation".

The promise of emancipation/empowerment has been referred to as a "universaling concern" (Gore 1993, 46). As such, it assumes a "vision or desirable end state" (Gore 2003, 333) and a certain type of subject of education - the rational individual (Ellsworth 1989; Gore 1993; Luke and Gore 1992). Charles Taylor (1989) describes the rational individual as "self defined by the powers of disengaged reason - with its associated ideals of self-responsible freedom and dignity - of self-exploration, and of personal commitment" (Taylor 1989, 211).

On the surface it is difficult to argue against the rational subject able to envision and argue towards a desirable end state. This is the problem that first faced feminist critics of critical pedagogy. Initially, they argued that the rational subject of the emancipatory principle is predicated upon the exclusion of the "irrational Other - women, peopleof-color, nature, aesthetics" (Ellsworth 1989, 305). This exclusion thus effectively silenced those who were not the masculinist subject of critical pedagogy "which renders its emancipatory agenda for 'gender' theoretically and practically problematic" (Luke 1992, 25). Feminist critical pedagogues turned to poststructuralist theory to address the problem of the rational subject of emancipation of critical pedagogy.

In drawing on poststructuralist theory, instead of assuming a rational subject as essential to emancipation, feminist critical pedagogues acknowledge that to become a subject is a process imbued with power. Specifically, the poststructuralist subject is understood as "produced socially through language in relations" (St. Pierre 2000, 504). This understanding of the human subject displaces the idea of the rational and all-knowing subject with the idea of a subject in constant production in relation to discourses and moments themselves imbued with relations of power. This shift enables us to explore how "we take up or resist certain subject positions that are readily available" (ibid, 502). In this way, power and resistance is understood as productive rather than oppressive (Pittard 2015, 330).

In taking this view of the subject as a productive process we can change how we do critical pedagogy. The "promise" of emancipation is not to a universalist vision but becomes the promise of studying how we become subjects and the search for different forms of being subjects. Michel Foucault (1983) describes such a study in the following manner:

The conclusion would be that the political, ethical, social and philosophical problem of our days is not to try to liberate the individual from the state, and from the state's institutions, but to liberate us both from the state and from the type of individualisation linked to the state. We have to promote new forms of subjectivity through the refusal of this kind of individuality that has been imposed on us for centuries. (Foucault 1983, 217) 
Emancipation, in this sense, is liberation from subjectivity and towards experimenting with subjectivity. Critical pedagogy can become an explicit examination of subject positions, how these positions are imposed and the struggle for different subject positions. Students do not merely acknowledge important issues but "explore alternative discourses, identities and futures" (Pavlenko 2004, 63). This includes examining the subject positions of critical pedagogy itself. With students we can turn a "critical eye towards critical pedagogy [with the aim to] open up subjective possibilities" (Pittard 2015, 330). And, again following Foucault, this means looking at our resistances to critical pedagogy in order to reveal different ways of doing critical pedagogy.

It consists in taking the forms of resistance against different forms of power as a starting point. To use another metaphor, it consists of using this resistance as a chemical catalyst so as to bring to light power relations, locate their position, find out their point of application and the methods used. (Foucault 1983, 211)

We suggest that emancipation in critical pedagogy does not involve direct, political dialogue and/or assessment tasks that may alienate students (Blignaut 2014) but the work of understanding how we become subjects of knowledge, including the knowledge of critical pedagogy. This method of doing critical pedagogy begins in an examination of resistances.

The method of examining subject positions and their effects and the attempt to experiment with different subjectivities can be used as the basis of an introductory critical pedagogy. Students can consider how they have previously learnt English and the effects of this upon who they are and who they are expected to be. This includes looking at reasons for learning English, the examination of culture and the effect of learning English upon a sense of self. Next, students can explore the critical pedagogy paradigm, its principles, the differences from past experiences of learning and the expectations of students and teachers. Lastly, students can examine the different subject positions in critical pedagogy and explore the limitations of these and think about different subject positions. The type of assessment tasks could include developing websites/essays/group presentations about the expectations of being students in a particular culture and how these compare to critical pedagogy expectations.

This form of curriculum work can be done in small groups in order to encourage knowledge negotiation - something the Korean students struggled with but then embraced. It is true that group work can be extremely stressful for students, as Kim found. $\mathrm{Li}$ (1998) discusses the issue of resistance in communicative English language learning classes in Korea. Beckett and Slater (2005) also claim that students involved to a degree in student-centred activities experience confusion and resistance due to different learner roles and learning processes. An antidote to this is to teach explicitly about the expectations of group work and knowledge negotiation. It will help if understandings about group work are part of the assessment, for example, students can draw up contracts that make them responsible for a particular role in the group. Individual marks instead of or alongside group marks can also be offered. 
As a complement to the vocal dialogue expected in critical pedagogy, reflective writing needs to be an aspect of the curriculum and of group work. Pavlenko (2004, 55) "calls into question the privilege given to talk versus silence and to the public use of language versus private reflection". Given the previous experiences of the students in the study with grammar/translation, and given the enthusiasm for reflective journals, we suggest that students be encouraged to write group journals about their experiences of knowledge negotiation. While we agree that there are ethical issues around student journals (Ghaye 2007; Pollard 2008) we believe that in the case of new and radical pedagogies they have proven a friend to the student. Such reflections work well when they form part of the assessment and we suggest both individual- and group-based reflective assessments.

\section{THE TEACHER AS FACILITATOR}

One of the hardest aspects of critical pedagogy for Kim was the shift to a radically different style of teaching. Kim had experienced, and been rewarded for, a directive style of teaching in which "the responsibility for deciding what and how students should learn rests solely with the teacher" (Blignaut 2014, 272). Critical pedagogy demands a significantly different role for teachers. Following a strict critical pedagogical approach requires teachers to aim towards a subversive transformation of social understandings and to be reflective about their own identity and beliefs (Yumarnamto 2013). The new style of teacher as facilitator was an extremely stressful shift for Kim, exemplified by receiving no recognition on Teachers' Day. The difficulties included students feeling frustrated that they were not receiving the type of instruction they were used to, Kim feeling angry when students expressed themselves and quite simply the difficulty of acting in a facilitation role for a class of 47 students.

Blignaut (2014) experienced similar difficulties. His teacher-education students in South Africa were angry about having to adopt a far more active approach to their learning and were disappointed with the role Blignaut took as a teacher. While there were some students who appreciated the new style of teaching and learning, overall, Blignaut claims that this new "approach to teaching for students was often fraught with uncertainty and a degree of anxiety" (277). It was also a fraught endeavour for the teacher. Teaching in this new manner was gruelling for Blignaut. His student evaluations were dismal and one student even laid a formal complaint. However, Blignaut was determined to continue and was supported in this by his belief that this new style of teaching was a necessary step towards a new post-apartheid South Africa. "After serious consideration I am convinced that it would be a mistake to give up and revert to more comfortable approaches" (280).

Kim adapted and developed the role of facilitator as the project progressed. Adaptations were made based on information received from student journals about their considerable frustrations at not learning in the usual manner and through Kim's 
reflections. She took a much more fluid approach to the notion of facilitation than she had expected. She used worksheets that contained detailed and clear instructions including the estimated time the task should take and she used popular songs to signal how much time had passed and was left. These simple innovations enabled Kim to garner a measure of control while still maintaining a student-centred pedagogy. Her need to adapt contributed to her feeling that she was failing in the role of facilitator. However, it is exactly this fluid type of role for the teacher that we suggest.

This type of teacher control in student-centred pedagogy might seem contradictory. Freedman (2007) argued that it is exactly what Freire's critics argued when Freire proposed that teachers "must always, at least to some extent, be "directive in their classroom"' (Freire and Macedo 1995, 378 quoted in Freedman 2007, 448). Freire's critics responded that he could not have it both ways: "Teachers cannot be both equal partners in dialogue and directors of classroom discourse" (Freedman 2007, 448). Like Freedman, we believe that teachers can be both equal partners and directors. Freedman responds that dialogue can work with a directive teacher, "[s]o long as everyone remains open to the possibility that their original convictions may have been misguided" (449). This dovetails with the method of inquiry into subject positions we have described above. Teachers are equal partners if they, along with students, are examining and experimenting with subject positions.

In terms of adapting to the new role for teachers, Tinning (2002) suggests the need for those new to the facilitator role to ask "what, in a negotiated curriculum, is actually not negotiable (i.e. teacher controlled and defined)" (emphasis in original, 230). Teachers need to understand where they are being directive and to ensure that students know why and where. Teachers might choose to be directive; they teach about the method, they offer some instructions suited to students' previous experiences and they can mediate texts and concepts that prove difficult for students. The latter is what Lin (2004) found necessary when introducing critical pedagogy to teacher-education students in Hong Kong. The required text proved quite difficult to students so, after some agonising, Lin wrote guiding questions that she gave to the students prior to their reading. This might be considered directive as Lin's interpretation is privileged. However, it was simply a necessity and one that Lin would repeat.

Furthermore, concerning the subject position of teacher as facilitator we would argue that it is simply that - a subject position open to challenge and experimentation. Erica McWilliam (2009) provides an interesting place to begin to consider that the teacher as facilitator is a confining role and could give way to the teacher as meddler-inthe middle. This approach to teaching aims at supporting students to "learn-to-be", as opposed to "learning-about" (McWilliam 2009, 286). This is an active style of learning that, in the case of critical pedagogy, aims to support students to "learn-to-be" critical. This type of teaching and learning requires a different form of teaching. The teacher as facilitator gives way to a meddler-in-the-middle position. McWilliam argues that teachers as facilitators, or "Guide[s]-on-the side", run the risk of excusing themselves 
from teaching. "When this occurs, Guide-on-the-Side becomes a high moral-ethical excuse for the teacher to 'step out' of the main game of teaching, and to sit at the margins of the physical, mental and emotional activity that is so vital to learning" (287). On the other hand, the meddler-in-the-middle is an "active interventionist pedagogy in which teachers are mutually involved with students in assembling and/or dis-assembling knowledge and cultural products" (288). The meddler becomes a co-producer of knowledge with the students. This is a role conducive to a modest pedagogy.

Finally, on this topic, the subject position of facilitator is difficult in large classes. According to Clifton $(2006,147)$, "facilitation is perhaps best suited to small groups of motivated, mature, relatively advanced learners working in an environment in which having more responsibility for learning is culturally acceptable". This was not the experience of Kim and her adaptations to a role of half-facilitator/half-director provides a glance at the future of critical pedagogy in non-Western contexts and can be seen as a type of meddler-in-the-middle compromise. A meddler, by default, is able to give directions if required, is able to actively assemble and dissemble knowledge/products with students and is able to change curriculum according to the cohort of students. While large classes may pose more problems to this style of teaching than foreseen by McWilliam, meddling offers greater possibilities than the more rigid role of facilitator.

\section{TOWARDS A MODEST PEDAGOGY}

In this paper we examined a case study of the resistances experienced in a project aimed at introducing critical pedagogy to an EFL class in Korea and have made suggestions for a localised version of critical pedagogy based in experiences and critiques. The localised version we have developed is aligned to a "modest critical pedagogy" (Tinning 2002), a form of critical pedagogy that avoids the promise of collective emancipation and offers a "more sceptical, less utopian" (ibid, 227) vision. Reviewing Kim's project has allowed us to articulate "details of what such a pedagogy might look like in practice" (Tinning 2002, 237). We believe a modest pedagogy needs to support the principles of critical pedagogy - "socially critical subject matter, negotiation, reflection and praxis" (ibid, 230). However, a modest critical pedagogy can introduce these principles through an examination of critical pedagogy itself. We have suggested that this can be achieved through examining the subject positions expected in critical pedagogy and experimenting with different subjectivities.

\section{CONCLUSION}

In this paper we have suggested the need for a modest critical pedagogy for introducing critical pedagogy to teacher-centred contexts. This form of critical pedagogy focuses on learning about critical pedagogy and re-shaping the paradigm as we do so. In particular, we have taken a poststructuralist approach to a modest critical pedagogy that argues critical pedagogy assumes certain subject positions for teachers and students and that 
this assumption can form the basis of critical pedagogy. We have used the work of Michel Foucault to suggest a critical pedagogy that examines its own limitations and attempts to move beyond them. This method begins with an examination of resistances. In this way, resistances are expected and become the very stuff of the curriculum. Students examine how they previously were taught and the role this expected of them in the learning process. Students and teachers are expected to examine the proposed subjects; these are expected to be within the critical pedagogy paradigm and students must consider how this impacts upon their sense of self and their learning of English. We suggested that group work and reflective writing be an aspect of the curriculum and assessment. There is further research required to develop this pedagogy and to see how it works with students.

We have argued that teachers ought not to feel that they have failed if they are more directive than expected. The role for the teacher in a modest critical pedagogy is less one of a facilitator and more of a half-and-half, looking towards a different subjectivity altogether. We have suggested that McWilliam's (2009) meddler-in-the-middle concept is of interest and bears further investigation. We encourage those teachers wishing to introduce a modest critical pedagogy to explore with students this new style of teaching and to be explicit about direction and facilitation.

Introducing a new form of pedagogy will always be fraught. The modest critical pedagogy suggested here makes resistances a central feature of the curriculum. In the case we have presented, EFL in Korea, we do not think that learning English, which is the reason for the course, will be cast aside in favour of doing critical pedagogy. The type of examination of subjectivity we suggest can be done whilst learning English. Is it any different from expecting students to develop websites on pressing social issues? In our case, the pressing social issue is the problem of subjectivity in relation to education.

\section{REFERENCES}

Auerbach, E. 1995. "The Politics of the ESL Classroom: Issues of Power in Pedagogical Choices." In Power and Inequality in Language Education, edited by J. Tollefson. Cambridge: Cambridge University Press.

Auerbach, E. 1996. Adult ESL/Literacy from the Community to the Community. New Jersey: Lawrence Erlbaum Associates.

Auerbach, E., and D. Burgess. 1985. "The Hidden Curriculum of Survival ESL." TESOL Quarterly 10 (4): 475-95.

Beckett, G. 2002. "Teacher and Student Evaluations of Project-Based Instruction.” TESL Canada Journal 19 (2): 52-66.

Beckett, G. 2005. “Academic Language and Literacy Socialization through Project-Based Instruction: ESL Students' Perceptions and Issues.” Journal of Asian Pacific Communication 15 (1): 191-206. 
Beckett, G., and T. Slater. 2005. "The Project Framework: A Tool for Language, Content and Skills Integration.” ELT Journal 59 (2): 108-16.

Blignaut, S. 2014. "Reflections on Student Resistance to a Constructivist Curriculum." Education as Change 18 (2): 271-83.

Block, D. 2004. "Key Concepts in ELT: Globalisation and Language Teaching.” ELT Journal 58 (1): 75-7.

Bogdan, R., and S. Biklen. 2003. Qualitative Research for Education: An Introduction to Theories and Methods. 4th ed. New York: Pearson Education group.

Canagarajah, S. 1999. Resisting Linguistic Imperialism in English Teaching. Oxford: Oxford University Press.

Chiu, Y. C. J. 2009. "Facilitating Asian Students' Critical Thinking in Online Discussions.” British Journal of Educational Technology 40 (1): 42-57.

Clifton, J. 2006. “Facilitator Talk.” ELT Journal 60 (2): 142-50.

Cook-Sather, A. 2002. "Authorising Students' Perspectives: Toward Trust, Dialogue, and Change in Education." Educational Researcher 31 (4): 3-14.

Cumming, A., and J. Gill. 1992. "Motivation or Accessibility? Facts Permitting Indo-Canadian Women to Pursue ESL Literacy Instruction.” In Socio-Political Aspects of ESL, edited by B. Burnaby and A. Cumming, 241-52. Toronto: OISE Press.

Currie, G., and D. Knights. 2003. "Reflecting on a Critical Pedagogy in MBA Education.” Management Learning 34 (1): 27-49.

Denzin, N. 1978. The Research Act: A Theoretical Introduction to Sociological Methods. $2^{\text {nd }}$ ed. New York: McGraw-Hill.

Derince, Z. 2011. "Language Learning through Critical Pedagogy in a 'Brave New World'.” International Review of Education 57: 377-95.

Ellsworth, E. 1989. "Why Doesn't This Feel Empowering? Working through the Repressive Myths of Critical Pedagogy." Harvard Educational Review 59 (3): 297-324.

Foucault, M. 1983. “Afterword: The Subject and Power.” In Michel Foucault: Beyond Structuralism and Hermeneutics, edited by H. Dreyfus and P. Rabinow. Chicago: University of Chicago Press

Freire, P. 1970. Pedagogy of the Oppressed. Ringwood: Penguin.

Freire, P. 1985. The Politics of Education: Culture Power and Liberation. London: Macmillan Publishers.

Freire, P., and D. Macedo. 1995. “A Dialogue: Culture, Language and Race.” Harvard Educational Review 65: 337-402.

Freedman, E. 2007. “Is Teaching for Social Justice Undemocractic?" Harvard Educational Review 77 (4): $442-528$. 
Ghaye, T. 2007. "Is Reflective Practice Ethical? (The Case of the Reflective Portfolio)." Reflective Practice: International and Multidisciplinary Perspectives 8 (2): 151-62.

Gore, J. 2003. "What Can We Do for You! What Can 'We' Do for 'You'?: Struggling over Empowerment in Critical and Feminist Pedagogy." In The Critical Pedagogy Reader, edited by A. Darder, M. Baltodano and R. Torres, 331-49. New York: Routledge Farmer.

Gore, J. 1993. The Struggle for Pedagogies: Critical and Feminist Discourses as Regimes of Truth. New York: Routledge.

Grande, S. 2015. Red Pedagogy: Native American Social and Political Thought. London: Rowman and Littlefield.

Hall, G. 1999. Redefining the Syllabus: An Investigation into Whether Syllabuses Can Meet Learners' Linguistic and Social Needs. Centre of Research in Language Education Papers, Department of Linguistics, Lancaster University.

Han, H. S. 2000. Yongo Kongyonghwa, Kwayon Kanung Han'ga (English as an official language, is it indeed possible?). Seoul: T'ukpyolsi: Ch`aek Sesang Hanguk Kyongjae.

Hiemstra, R. 2001. "Uses and Benefits of Journal Writing." In Promoting Journal Writing in Adult Education, edited by L. English and M. Gillen. San Francisco: Jossey-Bass.

Ivers, J. 2007. "Metacognition and Foreign Language Cultural Instruction." Journal of Transformative Education 5 (2): 152-62.

Kim, M. K. 2015. “Students' and Teacher's Reflections on Project-Oriented Learning: A Critical Pedagogy for Korean ELT.” English Teaching 70 (3): 73-98.

Knobel, M., and C. Lankshear. 2002. "Critical Cyberliteracies: What Young People Can Teach Us about Reading and Writing the World." Keynote paper prepared for the National Council of English Teachers' Assembly for Research Mid-Winter Conference. New York, February 22-24. http:// everydayliteracies.net/files/cyberliteracies.html (accessed March 5, 2015).

Kumashiro, K. 2015. Against Common Sense: Teaching and Learning toward Social Justice. $3^{\text {rd }}$ ed. London: Routledge.

Lave, J., and E. Wenger. 1991. Situated Learning: Legitimate Peripheral Participation. New York: Cambridge University Press.

Legutke, M., and H. Thomas. 1991. Process and Experience in the Language Classroom. London: Longman.

Li, D. 1998. “'It's Always More Difficult Than You Plan and Imagine': Teacher's Perceived Difficulties in Introducing the Communicative Approach in South Korea." TESOL Quarterly 32 (4): 677-703.

Lin, A. 2004. "Introducing a Critical Pedagogical Curriculum: A Feminist Reflexive Account." In Critical Pedagogies and Language Learning, edited by B. Norton and K. Toohey, 271-87. Cambridge: Cambridge University Press.

Liu, D. 1998. "Ethnocentrism in TESOL: Teacher Education and the Neglected Needs of International TESOL Students." ELT Journal 52 (1): 3-9. 
Luke, C., and J. Gore, eds. 1992. Feminisms and Critical Pedagogy. New York: Routledge.

Luke, C. 1992. "Feminist Politics in Radical Pedagogy.” In Feminisms and Critical Pedagogy, edited by C. Luke and J. Gore, 25-54. New York: Routledge.

McLaren, P. 1994. Life in Schools: An Introduction to Critical Pedagogy in the Foundations of Education. New York: Longman.

McWilliam, E. 2009. "Teaching for Creativity: From Sage to Guide to Meddler." Asia Pacific Journal of Education 29 (3): 281-93.

Ministry of Education (MOE). 2014. "Sagyoyuk Gyonggam mit Gonggyoyuk Jongsanghwa Daecha (Plans for reducing private tutoring and strengthening public schooling)." Seoul: MOE.

Nozaki, Y., R. Openshaw, and A. Luke. 2005. Struggles over Difference: Curriculum, Texts, and Pedagogy in the Asia-Pacific. Albany: SUNY Press.

Nunan, D. 1992. Research Methods in Language Learning. Cambridge: Cambridge University Press.

Park, J.-K., and M. K. Kim. 2014. "Teaching and Learning of EIL in Korean Culture and Context." In The Pedagogy of English as an International Language, edited by R. Marlina and R. Giri, 47-61. London: Springer.

Pavlenko, A. 2004. "Gender and Sexuality in Foreign and Second Language Education: Critical and Feminist Approaches." In Critical Pedagogies and Language Learning, edited by B. Norton and K. Toohey, 53-71. Cambridge: Cambridge University Press.

Pennycook, A. 1994. The Cultural Politics of English as an International Language. London: Longman.

Pennycook, A. 1996. “TESOL and Critical Literacies: Modern, Post, or Neo?” TESOL Quarterly 30 (1): $163-71$.

Pennycook, A. 1998. English and the Discourses of Colonialism. London: Routledge.

Pennycook, A. 2001. Critical Applied Linguistics: A Critical Introduction. New Jersey: Lawrence Erlbaum.

Phillipson, R. 1992. Linguistic Imperialism. Oxford: Oxford University Press.

Pittard, E. 2015. "Who Does Critical Pedagogy Think You Are? Investigating How Teachers Are Produced in Critical Pedagogy Scholarship to Inform Teacher Education." Pedagogies: An International Journal 10 (4): 328-48.

Pollard, V. 2008. "Ethics and Reflective Practice: Continuing the Conversation." Reflective Practice: International and Multidisciplinary Perspectives (9) 4: 399-407.

Power, B. 1996. Taking Notes: Improving Your Observational Note Taking. York: Stenhouse.

Reynolds, M. 1999. "Grasping the Nettle: Possibilities and Pitfalls of a Critical Management Pedagogy." British Journal of Management 10 (2): 171-84. 
Rivera, K. 1999. "Popular Research and Social Transformation: A Community-Based Approach to Critical Pedagogy.” TESOL Quarterly 33 (3): 485-500.

Samuel, K. 2000. Korea’s Globalization. Cambridge: Cambridge University Press.

Shafer, L. 1995. “Anecdotal Record Keeping: Learning from Rosa, Ahmed, and Zhou.” GWRC Journal 19: 16-23.

Shin, G. G. 2003. "The Cost of English Divide of Korea." Korean Teachers of English to Speakers of Other Languages (KOTESOL) Jeolla Chapter Meeting. http://gshin.chonnam.ac.kr/research/KATE5_ jeonra.ppt (accessed March 5, 2015).

St Pierre, E. 2000. "Poststructural Feminism in Education: An Overview." International Journal of Qualitative Studies in Education 13 (5): 477-515.

Sunchon National University. 2013. "Sunchon National University Revolutionary Learning Experience. (Haknyondo Sunchon Daehakkyo Sugi Gongmojon)." Sunchon, Jonnam: Kichogyoyukwon Gyosuhaksup Gaebalsente (Center for Teaching and Learning, Institute of General Education, Sunchon National University).

Sung, K. 2008. "A Study on Culture Teaching and Learning through the Analyses of ELT Materials and Survey.” English Language Teaching 20 (4): 209-235.

Taylor, C. 1989. Sources of the Self: The Making of the Modern Identity. Cambridge: Cambridge University Press.

Tinning, R. 2002. "Toward a 'Modest Pedagogy': Reflections of the Problematics of Critical Pedagogy." Quest (54) 3: 224-40.

Tollefson, J., ed. 1995. Power and Inequality in Language Education. Cambridge: Cambridge University Press.

Wallerstein, N. 1983. Language and Culture in Conflict: Problem-Posing in the ESL Classroom. Massachusetts: Addison-Wesley.

Warschauer, M. 1997. "A Sociocultural Approach to Literacy and Its Significance for CALL." In Nexus: The Convergence of Research and Teaching through New Information Technologies, edited by K. Murphy-Judy and R. Sanders, 88-97. Durham: University of North Carolina.

Warschauer, M. 2000. "The Changing Global Economy and the Future of English Teaching." TESOL Quarterly 34 (3): 511-35.

Wong, N. Y. 2008. "Confucian Heritage Culture Learner's Phenomenon: From 'Exploring the Middle Zone' to 'Constructing a Bridge'." Mathematics Education 40: 973-81.

Yumarnamto, M. 2013. "Critical Pedagogy in TESL/TEFL: How Far Can We Go?" Beyond Words 1 (1): $1-22$. 